\title{
Advantages and pitfalls of clinical application of sugammadex
}

\section{Hyung Young Lee and Ki Tae Jung}

Received November 27, 2019

Revised May 25, 2020

Accepted June 2, 2020
Department of Anesthesiology and Pain Medicine, School of Medicine, Chosun University, Gwangju, Korea

\author{
Corresponding author \\ Ki Tae Jung, M.D., Ph.D. \\ Department of Anesthesiology and \\ Pain Medicine, Chosun University \\ Hospital, School of Medicine, Chosun \\ University, 365 Pilmun-daero, Dong- \\ gu, Gwangju 61453, Korea \\ Tel: 82-62-220-3223 \\ Fax: 82-62-223-2333 \\ E-mail:mdmole@chosun.ac.kr
}

\begin{abstract}
Sugammadex, a modified $\gamma$-cyclodextrin, is one of the drugs focused on in the anesthetic field because it provides rapid and complete reversal from neuromuscular blockade (NMB) by encapsulating rocuronium. Its introduction has revolutionized anesthesia practice because it is a safe, predictable, and reliable neuromuscular antagonist. Hence, its use has increased worldwide. Further, it has been in the spotlight for recovering from deep NMB in laparoscopic surgery and improving the surgical condition. Recently, studies have been conducted on the postoperative outcome after deep NMB and use of sugammadex in various clinical conditions. However, with increase in sugammadex use, reports regarding its complications are increasing. Appropriate dosing of sugammadex with quantitative neuromuscular monitoring is emphasized because under-dosing or over-dosing of sugammadex might be associated with unexperienced complications. Sugammadex is now leaping into an ideal reversal agent, changing the anesthesia practice.
\end{abstract}

Keywords: Complications; Neuromuscular blockade; Review; Rocuronium; Sugammadex.

\section{INTRODUCTION}

Sugammadex, a modified $\gamma$-cyclodextrin, is a novel reversal agent with a selective binding capacity to steroidal neuromuscular blocking drugs (NMBDs) such as rocuronium. It has been in the spotlight as a novel reversal agent since discovery because of the quality of recovery from neuromuscular blockade (NMB), which is rapid, reliable, and less side effects [1,2]. In addition, it aids in optimizing the surgical condition during laparoscopic surgery [3]. It has been nearly 10 years since sugammadex was introduced clinically. Hence, the known benefits and new areas of interest in its clinical use are presented in this review.

\section{CLINICALLY SPOTLIGHTED ADVANTAGES OF SUGAMMADEX}

\section{Role of sugammadex in difficult airway management}

Researchers developed the idea of using sugammadex in the "cannot intubate, cannot ventilate" state because it rapidly reverses NMB [4-6]. As the prescription guideline represent that sugammadex can reverse successfully 3 min after rocuronium administration for the intubation when it is used as $16 \mathrm{mg} / \mathrm{kg}$, it could be one of the rescue management in the emergency situation of airway management after use of rocuronium. However, many researchers have suggested that sugammadex cannot be a part of the difficult airway algorithm and should not be used as the "silver bullet" for difficult airway management, instead alternative strategies such as surgical air- 
way should be considered [7-10].

\section{Effect of sugammadex on QTc}

Conventional reversal with neostigmine and atropine is associated with significant corrected QT (QTc) prolongation. On the contrary, sugammadex has nearly no effect on QTc [11]; however, it has some effect on QT prolongation [12]. In the case of Brugada syndrome, neostigmine or pyridostigmine can increase parasympathetic drive and lead to bradycardia [13]. Hence, sugammadex seems to be an ideal NMB reversal agent in Brugada syndrome.

\section{Specific disease and sugammadex}

Sugammadex provides rapid and reliable reversal from NMB and therefore, it has been successfully introduced for patients with neuromuscular disease or those with potential for postoperative respiratory dysfunctions such as Duchenne muscular dystrophy [14], amyotrophic lateral sclerosis [15], and myasthenia gravis [16-18]. In addition, its introduction for short-term muscle relaxation during electroconvulsive therapy (ECT) decreased the time to restoration of spontaneous ventilation and side effects of ECT $[19,20]$. Hence, use of sugammadex as a safe NMB reversal agent is expanding among patients with significant comorbidities.

\section{USE OF SUGAMMADEX IN A SPECIAL CLINICAL SITUATION}

\section{Optimal dose of sugammadex for an obese patient}

It is well known that the appropriate dose of sugammadex is consistent with the NMB status, which is determined by neuromuscular monitoring. Under-dosing may lead to residual NMB (RNMB), thus requiring an additional dose for complete reversal. However, the optimal dose of sugammadex for obese patients is under debate. Van Lancker et al. [21] compared the extubation time among morbidly obese patients administered with different doses (set by real body weight, ideal body weight [IBW], IBW $+20 \%$, and IBW $+40 \%$ ) of sugammadex and concluded that a dose of $2 \mathrm{mg} / \mathrm{kg}$ of IBW $+40 \%$ resulted in safe recovery from NMB. In addition, Llauradó et al. [22] reported that sugammadex dose calculated by IBW is insufficient for reversing both deep and moderate NMBs in morbidly obese patients. Badaoui et al. [23] reported that the dose of sugammadex for the reversal of deep NMB in the obese patient was $130-150 \%$ of weight based dosage (4 mg/ calculated IBW). However, other researchers have questioned the methodology and results [24]. Sanfilippo et al. [25] reported that sugammadex doses calculated based on only IBW are sufficient for rapid and safe NMB reversal, with no RNMB. A recent study demonstrated that sugammadex dosed at $1.5 \mathrm{mg} / \mathrm{kg}$ of IBW successfully reversed moderate NMB in obese patients [26]. In addition, Duarte et al. [27] concluded that IBW can be used to calculate the sugammadex dose to reverse moderate NMB in morbidly obese patients. However, despite these controversies, sugammadex should be administered based on the NMB status with quantitative neuromuscular monitoring before as well as after sugammadex administration [28].

\section{Drug interaction with sugammadex}

A concern that magnesium sulfate can affect rocuronium-induced NMB reversal with sugammadex existed because magnesium potentiates NMB [29]. However, a randomized study demonstrated that magnesium did not alter the efficacy of sugammadex [30]. In addition, effective and complete reversal of rocuronium-induced NMB with sugammadex $(2 \mathrm{mg} / \mathrm{kg})$ was observed in a pregnant woman treated with magnesium $(60 \mathrm{mg} / \mathrm{kg})$ intraoperatively [31]. Further, it was reported that pretreatment with magnesium did not significantly affect sugammadex reversal time for moderate NMB [32]. In addition, magnesium did not affect the reversal effects of sugammadex in animal studies $[33,34]$. However, administration of magnesium after rocuronium-induced NMB reversal with sugammadex may lead to recurarization, requiring continuous neuromuscular monitoring [35].

Sugammadex was developed from cyclodextrins, which were used to dissolve steroids, and therefore, there were concerns regarding interaction between sugammadex and steroids. Recently, a study reported concerns regarding the potential risk of contraception failure with estrogen or progestogen containing oral contraceptives after sugammadex use [36]. According to in vitro studies, sugammadex may bind to progestogen and therefore, progestogen exposure would decrease after sugammadex use. Administration of a bolus of sugammadex is considered equivalent to a missing dose of oral contraceptives. It is recommended that an 
additional, non-hormonal contraceptive or alternative birth control method should be used for 7 days after sugammadex is administered to a patient taking an oral contraceptive. However, clinical data related to pregnancy is lacking. In animal studies, sugammadex did not affect pregnancy or progesterone levels in pregnant rats in the first trimester [37]. In addition, no changes in the clinical course of pregnancy and no stillbirth or miscarriage were noted. A randomized clinical study demonstrated that sugammadex is not associated with adverse effects on steroid hormones such as progesterone and cortisol, except for a temporary increase in aldosterone and testosterone levels [38]. However, whether to include this matter in the consent form is still under debate.

\section{Can we use sugammadex in the patient with renal failure?}

According to the prescriber's information, because the sugammadex-rocuronium complex is eliminated mainly by renal excretion, severe renal failure is a contraindication. In a patient with creatinine clearance less than $30 \mathrm{~mL} /$ min, urinary excretion of the sugammadex-rocuronium complex was found to be reduced [39] and potential dissociation of the complex was noted. However, the recovery time (train-of-four [TOF] ratio: 0.9 ) after using sugamma$\operatorname{dex}(2 \mathrm{mg} / \mathrm{kg})$ was not significantly different between patients with renal impairment and normal patients $(0.9-2$ min vs. $1.65 \mathrm{~min}$ ) as well as no RNMB was noted [40]. According to a pharmacokinetic study, there are large differences in the pharmacokinetics of rocuronium and sugammadex between patients with severe renal failure and healthy controls [39]. Lobaz et al. [41] reported that failure of NMB reversal was successfully managed using sugammadex in an elderly patient with severe renal failure. Furthermore, in another patient with severe renal failure, sugammadex was successfully used as a rescue following prolonged NMB with recurarization [41]. In an animal study, sugammadex rapidly and effectively reversed rocuronium-induced NMB in cats with both renal pedicles ligated [42]. A study reported that although sugammadex could rapidly reverse NMB without recurarization in patients with renal failure, the urinary excretion of rocuronium and sugammadex was reduced and total plasma clearance was considerably lower in patients with renal failure compared with controls [39]. Moreover, no clinical data on long-term disposition of the sugammadex-rocuronium complex, which is retained in the body of a patient with renal failure, are available. Thus, although the sugammadex-rocuronium complex is dialysable through high-flux dialysis [43], the use of sugammadex in patients with severe renal failure should be carefully considered, with appropriate postoperative neuromuscular monitoring [44,45]. Recently, in an elderly patient with end-stage renal failure, erratic infiltration of subcutaneous rocuronium was successfully managed with sugammadex and the duration of action was sufficient to neutralize the ongoing absorption of subcutaneous rocuronium [46].

\section{Failure of reversal, recurarization, and resensitization?}

Sugammadex is considered as a novel and promising drug for reversal of rocuronium-induced NMB. However, some studies have reported delayed recovery with sugammadex, wherein time intervals after administration of sugammadex ( $4 \mathrm{mg} / \mathrm{kg}$ ) were reported to be 24.6 and 22.3 min until recovery of TOF ratio to $0.9[47,48]$. These unexpected long recovery times were often associated with inadequate neuromuscular monitoring and under-dosing of sugammadex. In addition, they were associated with the old age of patients, slow hemodynamic circulation, pulmonary disease, obesity, and renal failure in some cases [49]. However, cases of failure of sugammadex to reverse rocuronium-induced NMB have begun to be reported. Ortiz-Gómez et al. [50] reported a case of failure to reverse NMB with a large dose of sugammadex $(9.74 \mathrm{mg} / \mathrm{kg})$. Further, they suggested that this might be an "extreme outlier" with a marked rightward shift of the dose-response curve and there would be cases in which rapid reversal cannot be achieved with sugammadex. Interestingly, Carollo and White [51] reported a case of recurarization after administration of an adequate dose of sugammadex in an 8-month-old baby. Sugammadex was dosed at $4 \mathrm{mg} / \mathrm{kg}$ for NMB reversal with a TOF count of 2 and reversal was achieved rapidly; however, respiratory failure and a decline in the TOF response (TOF count: 2 ) were observed during the recovery in the intensive care unit. Recently, a report indicated that rescue administration of sugammadex (200 mg) after administration of neostigmine (50-70 $\mathrm{mg} / \mathrm{kg}$ ) for NMB reversal can result in a paradoxical reduction in the TOF ratio. This is because complete removal of rocuronium from the neuromuscular junction by sugammadex may lead to a desensitized block, similar to a phase-2 block, due to excessive intrasynaptic acetylcho- 
line made available after high-dose neostigmine administration [52].

\section{Can we use sugammadex in rocuronium-induced anaphylaxis?}

In contrast to the anaphylaxis due to sugammadex, Jones and Turkstra [53] suggested the possibility of using sugammadex in the case of rocuronium-induced anaphylaxis. They suggested that the property of sugammadex to encapsulate rocuronium can be a rationale for effectively removing free rocuronium molecules from the circulation and slowing down or halting the immunological process. This suggestion was clinically applied by McDonnell et al. [54]. They administered sugammadex (500 $\mathrm{mg}$ ) to a patient with cardiovascular collapse due to an anaphylactic reaction to rocuronium during anesthesia induction and found that sugammadex improved the hemodynamic state. Moreover, another case of rocuronium-induced anaphylaxis with clinical improvement triggered by sugammadex was reported [55]. However, it was believed that sugammadex would not mitigate rocuronium-induced anaphylaxis because according to an in vitro study, encapsulation of rocuronium by sugammadex does not stop basophil activation by the rocuronium [56]. The antigenic portion of the rocuronium molecule containing the ammonium group protrudes from the cyclodextrin host, thereby exposing the ammonium group to the complementary immunoglobulin E (IgE) antibodies $[56,57]$. However, despite these debates, successful management of rocuronium-induced anaphylactic reactions with sugammadex has been continuously reported [58], even in the case of refractory to conventional treatment [59]. According to the cutaneous model of anaphylaxis in rocuronium-sensitized patients, sugammadex was effective in attenuating the type-1 hypersensitivity reaction triggered by rocuronium [60]. In an animal study, the degranulation of mast cells in the rat liver, which were increased in numbers by rocuronium, was mitigated by sugammadex [61]. An intradermal injection of sugammadex and rocuronium, mixed in an equal molecular ratio, prevented rocuronium-induced IgE-mediated anaphylactic skin reaction [62]. These studies suggested that sugammadex may be beneficial for treating rocuronium-induced anaphylaxis. However, not all patients with rocuronium-induced anaphylaxis recovered rapidly with sugammadex. In addition, Raft et al. [63] reported that even large doses (14 $\mathrm{mg} / \mathrm{kg}$ ) of sugammadex did not induce recovery from anaphylaxis. Hakozaki and Murakawa [64] reported that a low dose of sugammadex could not improve rocuronium-induced anaphylaxis. The overall risk-benefit ratio seems to favor sugammadex administration in the rocuronium associated hypersensitivity with potentially life-threatening consequences [65]. However, one should be aware of the potential side effects of sugammadex, sugammadex-induced anaphylaxis.

\section{SIDE EFFECTS AND PRECAUTIONS OF SUGAMMADEX USE}

\section{Hypersensitivity and anaphylaxis}

Although hypersensitivity to sugammadex is a rare event, the consequences can be serious, such as cardiovascular collapse. Anaphylactic reaction associated with sugammadex was also reported in Korea [66], and now it is considered as an emerging trigger of perioperative anaphylaxis [67]. A systematic review on hypersensitivity associated with sugammadex suggests the possibility of hypersensitivity reaction and caution required during the critical 5-min period immediately following the administration because most of the cases have occurred within $5 \mathrm{~min}$ [68]. Moreover, a prompt treatment is required because it is not only easier to manage but also presents a better prognosis than a delayed treatment. However, because the biphasic anaphylactic attack can develop as a severe second attack, closed monitoring is required [69]. Hypersensitivity to sugammadex can be confirmed by an intradermal skin test with a 1:100 dilution or a 1:1,000 dilution of sugammadex [70-72]. The suggested investigative procedure is as follows: tryptase test of preoperative serum (at least one or two samples after the onset of symptoms), skin test, and immunoassay for sugammadex-reactive IgE antibodies [73]. However, studies have revealed that hypersensitivity is not always mediated with sugammadex-specific IgG or IgE $[74,75]$. Recently, it has been reported that sugammadex-associated anaphylaxis is not induced by sugammadex molecule alone but by the rocuronium and sugammadex complex and sugammadex molecule [76,77]. Thus, anesthesiologists should take more precautions.

\section{Acute coronary syndrome}

One of the noteworthy side effects of sugammadex is 
coronary vasospasm. Ko et al. [78] reported a case of coronary spasm in a patient with variant angina, which might have been triggered by sugammadex. However, a recent animal study suggested that sugammadex has no direct effect on the vascular tone [79]. Some researchers have thought that the effect of sugammadex on the coronary artery is due to hypersensitivity reactions such as Kounis syndrome [80,81]. Recently, a case of sugammadex-induced Kounis type III syndrome (hypersensitivity-induced acute coronary stent thrombosis) was reported [81]. Hence, anesthesiologists should consider acute coronary syndrome and should take precautions when using sugammadex for emergence from anesthesia.

\section{Pulmonary complications after sugammadex use}

Sometimes, the potency of sugammadex for rapid and reliable NMB reversal results in unwanted events such as pulmonary complications. Sugammadex has been reported to cause upper-airway obstructions such as laryngospasm or bronchospasm [82,83]. Suzuki et al. [84] reported a case of negative pressure pulmonary edema after sugammadex administration which might have been caused by increased upper airway collapsibility due to diaphragm-generated large inspiratory forces, decreasing pharyngeal patency. Eskander et al. [85] reported two cases of bronchospasm after coadministration of desflurane and sugammadex and suspected that desflurane-induced respiratory irritation may increase the risk of sugammadex-induced bronchospasm.

\section{Other potential risks of sugammadex}

Other potential risks of sugammadex, such as severe bradycardia, interactions with steroids, coagulopathy, and neuronal damage, are well described in a previous review [86]. The review suggested that administration of supratherapeutic doses of sugammadex results in these complications and presence of excessive sugammadex molecules in free-form might be associated with these risks.

\section{RECENT CLINICAL INTERESTS REGARDING SUGAMMADEX}

\section{Is deep NMB really beneficial?}

Recently, benefits of using sugammadex have been ques- tioned [87]. Most of the publications have presented limited advantages of sugammadex such as improved surgical conditions. However, the long-term effects of deep NMB for the surgical outcome or reduction in complication rates have not been well established. Moreover, a recent study reported no added benefit of deep NMB over moderate relaxation in bariatric surgery [88]. Another study reported marginal improvement in surgical conditions with deep NMB in low-pressure laparoscopic cholecystectomy [89]. Further, deep NMB with lower intra-abdominal pressure were reported to provide few cardiopulmonary benefits during laparoscopic colorectal surgery [90]. Moreover, deep NMB did not improve the surgical view during laparoscopic ventral hernia repair and showed benefits only during suturing of the hernial defect [91]. However, studies on post-surgical outcomes are recent. Oh et al. [92] reported that deep NMB not only improved the surgical condition but also reduced postoperative pain in lumbar spinal surgery. Mulier and Dillemans [93] revealed that continuous deep NMB is an independent factor associated with fewer complications after bariatric surgery. Kim et al. [94] reported that compared with neostigmine, sugammadex may increase the quality of physiological recovery in early postoperative periods after ophthalmic surgery. Boon et al. [95] reported that compared with use of low-dose NMBD, use of high-dose NMBD for anesthesia induction during retroperitoneal laparoscopic surgery and reversal with sugammadex showed a lower incidence of unplanned 30-day readmissions. Oh et al. [96] revealed that unplanned 30-day readmission after major abdominal surgery decreased with sugammadex use. Chae et al. [97] indicated that reversal with sugammadex decreased the incidence of delayed discharge.

\section{Intraoperative neuromonitoring and sugammadex}

These days, many surgical procedures require intraoperative neuromonitoring using a neural integrity monitor. In the case of ear, nose, and throat surgery, facial or recurrent laryngeal nerve monitoring is required for NMB reversal and sugammadex can be an option for the rapid and effective reversal from rocuronium-induced deep NMB [98-100].

\section{Economic issue and under-dosing techniques of sugammadex}

Although sugammadex is useful for the reversal of rocuronium-induced deep $\mathrm{NMB}$ and seems more reliable than 
neostigmine, it cannot replace neostigmine because it is expensive [101]. Interestingly, researchers are studying the use of under-dose of sugammadex as a cost-effective strategy [102]. However, although no report on the sugammadex under-dosing method for rocuronium-induced NMB reversal is available, some clinical trials have been reported. In addition, no study or evidence on the safety and cost-effectiveness of the sugammadex under-dosing method has been reported. Moreover, based on dose-finding studies, under-dosing of sugammadex is associated with $\mathrm{RNMB}$. A recent study revealed that elderly patients are at greater risk for RNMB when low-dose sugammadex is administered [103]. Hence, sugammadex should be dosed based on the quantitative analysis of neuromuscular monitoring [104].

\section{Sugammadex defiantly decreased the postoperative pulmonary complications}

Recent multicenter trials revealed that sugammadex defiantly decreased postoperative pulmonary complications in 45,712 adult patients undergoing noncardiac surgery [105]. The incidence of postoperative pulmonary complications such as pneumonia, respiratory failure, and pneumothorax was lower in the sugammadex group than that in the neostigmine group (3.5\% vs. $4.8 \%$; odds ratio, $0.70 ; 95 \%$ confidence interval, 0.63-0.77). Hence, lower incidence of RNMB with sugammadex use can be translated into lower incidence of postoperative pulmonary complications [106].

\section{CONCLUSION}

Use of sugammadex has increased worldwide since its introduction because it reverses NMB safely and reliably. Initially, it was in the spotlight because it reversed deep NMB in surgeries such as laparoscopic surgery. However, most of the studies were focused only on the surgical condition and a few studies were focused on sugammadex-associated surgical outcome or complication. Recently, studies are being conducted on postoperative outcomes after deep NMB and on the use of sugammadex in various conditions. Reports regarding sugammadex-associated complications are increasing with increase in its use and therefore, anesthesiologists should be vigilant of new complications. An anesthesiologist should be aware of interactions between sugammadex and other drugs and should consider conditions or disease of the patient. Primarily, an appropriate dose of sugammadex should be determined based on quantitative neuromuscular monitoring. Under-dosing or over-dosing of sugammadex should be avoided as it may lead to RNMB or other complications.

\section{CONFLICTS OF INTEREST}

No potential conflict of interest relevant to this article was reported.

\section{AUTHOR CONTRIBUTIONS}

Conceptualization: Ki Tae Jung. Data acquisition: Hyung Young Lee, Ki Tae Jung. Supervision: Ki Tae Jung. Writingoriginal draft: Hyung Young Lee, Ki Tae Jung. Writing-review \& editing: Ki Tae Jung.

\section{ORCID}

Hyung Young Lee, https://orcid.org/0000-0001-5861-3131

Ki Tae Jung, https://orcid.org/0000-0002-2486-9961

\section{REFERENCES}

1. Woo T, Kim KS, Shim YH, Kim MK, Yoon SM, Lim YJ, et al Sugammadex versus neostigmine reversal of moderate rocuronium-induced neuromuscular blockade in Korean patients. Korean J Anesthesiol 2013; 65: 501-7.

2. Della Rocca G, Pompei L, Pagan DE Paganis C, Tesoro S, Mendola C, Boninsegni P, et al. Reversal of rocuronium induced neuromuscular block with sugammadex or neostigmine: a large observational study. Acta Anaesthesiol Scand 2013; 57: 1138-45.

3. Martini CH, Boon M, Bevers RF, Aarts LP, Dahan A. Evaluation of surgical conditions during laparoscopic surgery in patients with moderate vs deep neuromuscular block. Br J Anaesth 2014; 112: 498-505.

4. Paton L, Gupta S, Blacoe D. Successful use of sugammadex in a 'can't ventilate' scenario. Anaesthesia 2013; 68: 861-4.

5. Wołoszczuk-Gębicka B, Zawadzka-Głos L, Lenarczyk J, Sitkowska BD, Rzewnicka I. Two cases of the "cannot ventilate, cannot intubate" scenario in children in view of recent recommendations. Anaesthesiol Intensive Ther 2014; 46: 88-91.

6. Mendonca C. Sugammadex to rescue a 'can't ventilate' scenario in an anticipated difficult intubation: is it the answer? An- 
aesthesia 2013; 68: 795-9.

7. Elliott SK, Ball DR. Sugammadex in anticipated difficult airways(2.). Anaesthesia 2013; 68: 1190.

8. Benham SW. Sugammadex in anticipated difficult airways(3.). Anaesthesia 2013; 68: 1190-1.

9. Dalton AJ, McGuire B, Rodney G. Sugammadex in anticipated difficult airways(4.). Anaesthesia 2013; 68: 1191-2.

10. Copp MV. Sugammadex in anticipated difficult airways(5.). Anaesthesia 2013; 68: 1192.

11. Dahl V, Pendeville PE, Hollmann MW, Heier T, Abels EA, Blobner M. Safety and efficacy of sugammadex for the reversal of rocuronium-induced neuromuscular blockade in cardiac patients undergoing noncardiac surgery. Eur J Anaesthesiol 2009; 26: 874-84.

12. Pühringer FK, Rex C, Sielenkämper AW, Claudius C, Larsen PB, Prins ME, et al. Reversal of profound, high-dose rocuronium-induced neuromuscular blockade by sugammadex at two different time points: an international, multicenter, randomized, dose-finding, safety assessor-blinded, phase II trial. Anesthesiology 2008; 109: 188-97.

13. Dendramis G, Paleologo C, Sgarito G, Giordano U, Verlato R, Baranchuk A, et al. Anesthetic and perioperative management of patients with Brugada syndrome. Am J Cardiol 2017; 120: 1031-6.

14. Wefki Abdelgawwad Shousha AA, Sanfilippo M, Sabba A, Pinchera P. Sugammadex and reversal of neuromuscular block in adult patient with duchenne muscular dystrophy. Case Rep Anesthesiol 2014; 2014: 680568.

15. Chang YJ, Jung WS, Son WR, Jo YY. Discordance between trainof-four response and clinical symptoms in a patient with amyotrophic lateral sclerosis. Acta Med Okayama 2014; 68: 125-7.

16. Sungur Ulke Z, Yavru A, Camci E, Ozkan B, Toker A, Senturk M. Rocuronium and sugammadex in patients with myasthenia gravis undergoing thymectomy. Acta Anaesthesiol Scand 2013; 57: 745-8.

17. Vymazal T, Krecmerova M, Bicek V, Lischke R. Feasibility of full and rapid neuromuscular blockade recovery with sugammadex in myasthenia gravis patients undergoing surgery - a series of 117 cases. Ther Clin Risk Manag 2015; 11: 1593-6.

18. Takeda A, Kawamura M, Hamaya I, Kitamura H, Muto R, Mitono H. [Case of anesthesia for thoracoscopic thymectomy in a pediatric patient with myasthenia gravis: reversal of rocuronium-induced neuromuscular blockade with sugammadex]. Masui 2012 61: 855-8. Japanese.

19. Grandjean B, Guerci P, Vial F, Raft J, Fuchs-Buder T, Bouaziz H. [Sugammadex and profound rocuronium neuromuscular blockade induced by magnesium sulphate]. Ann Fr Anesth Re- anim 2013 32: 378-9. French.

20. Saricicek V, Sahin L, Bulbul F, Ucar S, Sahin M. Does rocuronium-sugammadex reduce myalgia and headache after electroconvulsive therapy in patients with major depression? J ECT 2014; 30: 30-4.

21. Van Lancker P, Dillemans B, Bogaert T, Mulier JP, De Kock M, Haspeslagh M. Ideal versus corrected body weight for dosage of sugammadex in morbidly obese patients. Anaesthesia 2011; 66: $721-5$.

22. Llauradó S, Sabaté A, Ferreres E, Camprubí I, Cabrera A. Sugammadex ideal body weight dose adjusted by level of neuromuscular blockade in laparoscopic bariatric surgery. Anesthesiology 2012; 117: 93-8.

23. Badaoui R, Cabaret A, Alami Y, Zogheib E, Popov I, Lorne E, et al. Reversal of neuromuscular blockade by sugammadex in laparoscopic bariatric surgery: in support of dose reduction. Anaesth Crit Care Pain Med 2016; 35: 25-9.

24. Schmartz D, Guerci P, Fuchs-Buder T. Sugammadex dosing in bariatric patients. Anesthesiology 2013; 118: 754.

25. Sanfilippo M, Alessandri F, Wefki Abdelgawwad Shousha AA, Sabba A, Cutolo A. Sugammadex and ideal body weight in bariatric surgery. Anesthesiol Res Pract 2013; 2013: 389782.

26. Abd El-Rahman AM, Othman AH, El Sherif FA, Mostafa MF, Taha O. Comparison of three different doses sugammadex based on ideal body weight for reversal of moderate rocuronium-induced neuromuscular blockade in laparoscopic bariatric surgery. Minerva Anestesiol 2017; 83: 138-44.

27. Duarte NMDC, Caetano AMM, Neto SDSC, Filho GRO, Arouca GO, Campos JM. [Sugammadex by ideal body weight versus $20 \%$ and $40 \%$ corrected weight in bariatric surgery - double-blind randomized clinical trial]. Rev Bras Anestesiol 2018 68: 219-24. Portuguese.

28. Ledowski T. Sugammadex: what do we know and what do we still need to know? A review of the recent (2013 to 2014) literature. Anaesth Intensive Care 2015; 43: 14-22.

29. Bom A, Hope F, Rutherford S, Thomson K. Preclinical pharmacology of sugammadex. J Crit Care 2009; 24: 29-35.

30. Czarnetzki C, Tassonyi E, Lysakowski C, Elia N, Tramèr MR. Efficacy of sugammadex for the reversal of moderate and deep rocuronium-induced neuromuscular block in patients pretreated with intravenous magnesium: a randomized controlled trial. Anesthesiology 2014; 121: 59-67.

31. Song S, Yoo BH, Kim KM, Lee S. Reversal of rocuronium induced neuromuscular blockade using sugammadex in a patient with eclampsia treated by magnesium intraoperatively. Korean J Anesthesiol 2014; 67(Suppl): S102-3.

32. Germano Filho PA, Cavalcanti IL, Barrucand L, Verçosa N. Ef- 
fect of magnesium sulphate on sugammadex reversal time for neuromuscular blockade: a randomised controlled study. Anaesthesia 2015; 70: 956-61.

33. Kang WS, Kim KS, Song SM. Reversal with sugammadex for rocuronium-induced deep neuromuscular block after pretreatment of magnesium sulfate in rabbits. Korean J Anesthesiol 2017; 70: 203-8.

34. Sung TY, You HJ, Cho CK, Choi HR, Kim YB, Shin YS, et al. Effects of magnesium chloride on rocuronium-induced neuromuscular blockade and sugammadex reversal in an isolated rat phrenic nerve-hemidiaphragm preparation: an in-vitro study. Eur J Anaesthesiol 2018; 35: 193-9.

35. Unterbuchner C, Ziegleder R, Graf B, Metterlein T. Magnesium-induced recurarisation after reversal of rocuronium-induced neuromuscular block with sugammadex. Acta Anaesthesiol Scand 2015; 59: 536-40.

36. Corda DM, Robards CB. Sugammadex and oral contraceptives: is it time for a revision of the anesthesia informed consent? Anesth Analg 2018; 126: 730-1.

37. Et T, Topal A, Erol A, Tavlan A, Kılıçaslan A, Uzun ST. The effects of sugammadex on progesterone levels in pregnant rats. Balkan Med J 2015; 32: 203-7.

38. Gunduz Gul G, Ozer AB, Demirel I, Aksu A, Erhan OL. The effect of sugammadex on steroid hormones: a randomized clinical study. J Clin Anesth 2016; 34: 62-7.

39. Staals LM, Snoeck MM, Driessen JJ, van Hamersvelt HW, Flockton EA, van den Heuvel MW, et al. Reduced clearance of rocuronium and sugammadex in patients with severe to end-stage renal failure: a pharmacokinetic study. Br J Anaesth 2010; 104: 31-9.

40. Staals LM, Snoeck MM, Driessen JJ, Flockton EA, Heeringa M, Hunter JM. Multicentre, parallel-group, comparative trial evaluating the efficacy and safety of sugammadex in patients with end-stage renal failure or normal renal function. $\mathrm{Br} \mathrm{J}$ Anaesth 2008; 101: 492-7.

41. Lobaz S, Sammut M, Damodaran A. Sugammadex rescue following prolonged rocuronium neuromuscular blockade with 'recurarisation' in a patient with severe renal failure. BMJ Case Rep 2013; 2013: bcr2012007603.

42. Staals LM, de Boer HD, van Egmond J, Hope F, van de Pol F, Bom AH, et al. Reversal of rocuronium-induced neuromuscular block by sugammadex is independent of renal perfusion in anesthetized cats. J Anesth 2011; 25: 241-6.

43. Cammu G, Van Vlem B, van den Heuvel M, Stet L, el Galta R, Eloot S, et al. Dialysability of sugammadex and its complex with rocuronium in intensive care patients with severe renal impairment. Br J Anaesth 2012; 109: 382-90.
44. Panhuizen IF, Gold SJ, Buerkle C, Snoeck MM, Harper NJ, Kaspers MJ, et al. Efficacy, safety and pharmacokinetics of sugammadex $4 \mathrm{mg} \mathrm{kg}^{-1}$ for reversal of deep neuromuscular blockade in patients with severe renal impairment. Br J Anaesth 2015; 114: 777-84.

45. Min KC, Lasseter KC, Marbury TC, Wrishko RE, Hanley WD, Wolford DG, et al. Pharmacokinetics of sugammadex in subjects with moderate and severe renal impairment. Int J Clin Pharmacol Ther 2017; 55: 746-52.

46. Navare SR, Garcia Medina O, Prielipp RC, Weinkauf JL. Sugammadex reversal of a large subcutaneous depot of rocuronium in a dialysis patient: a case report. A A Pract 2019; 12: 375-7.

47. Sparr HJ, Vermeyen KM, Beaufort AM, Rietbergen H, Proost JH, Saldien V, et al. Early reversal of profound rocuronium-induced neuromuscular blockade by sugammadex in a randomized multicenter study: efficacy, safety, and pharmacokinetics. Anesthesiology 2007; 106: 935-43.

48. White PF, Tufanogullari B, Sacan O, Pavlin EG, Viegas OJ, Minkowitz HS, et al. The effect of residual neuromuscular blockade on the speed of reversal with sugammadex. Anesth Analg 2009; 108: 846-51.

49. Van Gestel L, Cammu G. Is the effect of sugammadex always rapid in onset? Acta Anaesthesiol Belg 2013; 64: 41-7.

50. Ortiz-Gómez JR, Palacio-Abizanda FJ, Fornet-Ruiz I. Failure of sugammadex to reverse rocuronium-induced neuromuscular blockade: a case report. Eur J Anaesthesiol 2014; 31: 708-9.

51. Carollo DS, White WM. Postoperative recurarization in a pediatric patient after sugammadex reversal of rocuronium-induced neuromuscular blockade: a case report. A A Pract 2019 doi: 10.1213/XAA.0000000000001023. [Epub ahead of print].

52. Szental JA, Bramley D. Neostigmine-induced weakness after sugammadex. Anaesthesia 2019; 74: 253.

53. Jones PM, Turkstra TP. Mitigation of rocuronium-induced anaphylaxis by sugammadex: the great unknown. Anaesthesia 2010 65: 89-90; author reply 90.

54. McDonnell NJ, Pavy TJ, Green LK, Platt PR. Sugammadex in the management of rocuronium-induced anaphylaxis. Br J Anaesth 2011; 106: 199-201.

55. Funnell AE, Griffiths J, Hodzovic I. A further case of rocuronium-induced anaphylaxis treated with sugammadex. Br J Anaesth 2011; 107: 275-6.

56. Leysen J, Bridts CH, De Clerck LS, Ebo DG. Rocuronium-induced anaphylaxis is probably not mitigated by sugammadex: evidence from an in vitro experiment. Anaesthesia 2011; 66: 526-7.

57. Baldo BA, McDonnell NJ, Pham NH. Drug-specific cyclodextrins with emphasis on sugammadex, the neuromuscular 
blocker rocuronium and perioperative anaphylaxis: implications for drug allergy. Clin Exp Allergy 2011; 41: 1663-78.

58. Kawano T, Tamura T, Hamaguchi M, Yatabe T, Yamashita K, Yokoyama M. Successful management of rocuronium-induced anaphylactic reactions with sugammadex: a case report. J Clin Anesth 2012; 24: 62-4.

59. Raft J, Leclercq M, Longrois D, Meistelman C. [Fast recovery of haemodynamic and ventilatory functions after sugammadex bolus following rocuronium-induced anaphylactic shock refractory to conventional treatment]. Ann Fr Anesth Reanim 2012; 31: 158-61. French.

60. Clarke RC, Sadleir PH, Platt PR. The role of sugammadex in the development and modification of an allergic response to rocuronium: evidence from a cutaneous model. Anaesthesia 2012; 67: 266-73.

61. Tomak Y, Yllmaz A, Bostan H, Tümkaya L, Altuner D, Kalkan Y, et al. Effects of sugammadex and rocuronium mast cell number and degranulation in rat liver. Anaesthesia 2012; 67: 11014.

62. Binczak M, Fischler M, Le Guen M. Efficacy of sugammadex in preventing skin test reaction in a patient with confirmed rocuronium anaphylaxis: a case report. A A Pract 2019; 13: 17-9.

63. Raft J, Belhadj-Tahar N, Meistelman C. Slow recovery after sugammadex bolus after rocuronium-induced anaphylaxis. $\mathrm{Br}$ J Anaesth 2014; 112: 1115-6.

64. Hakozaki T, Murakawa M. Rocuronium-induced anaphylaxis not improved by low dose sugammadex: a case report. Anaesth Intensive Care 2016; 44: 522.

65. Plaud B. A new option for the treatment of anaphylaxis linked to steroidal neuromuscular blockers: How much value should we grant to case reports? Can J Anaesth 2014; 61: 511-8.

66. Yoo JH, Kim SI, Ok SY, Park SY, Cho A, Han YM, et al. Suspected anaphylactic reaction associated with sugammadex: a case report. Korean J Anesthesiol 2016; 69: 413-6.

67. Ue KL, Kasternow B, Wagner A, Rutkowski R, Rutkowski K. Sugammadex: an emerging trigger of intraoperative anaphylaxis. Ann Allergy Asthma Immunol 2016; 117: 714-6.

68. Tsur A, Kalansky A. Hypersensitivity associated with sugammadex administration: a systematic review. Anaesthesia 2014; 69: $1251-7$.

69. Hori Y, Oi C, Yoshimura K, Sano H, Bepu Y. [A biphasic anaphylactic attack from sugammadex with a severe second attack]. Masui 2015 64: 619-21. Japanese.

70. Jeyadoss J, Kuruppu P, Nanjappa N, Van Wijk R. Sugammadex hypersensitivity-a case of anaphylaxis. Anaesth Intensive Care 2014; 42: 89-92.

71. Sadleir PH, Russell T, Clarke RC, Maycock E, Platt PR. Intraop- erative anaphylaxis to sugammadex and a protocol for intradermal skin testing. Anaesth Intensive Care 2014; 42: 93-6.

72. Nakanishi T, Ishida K, Utada K, Yamaguchi M, Matsumoto M. Anaphylaxis to sugammadex diagnosed by skin prick testing using both sugammadex and a sugammadex-rocuronium mixture. Anaesth Intensive Care 2016; 44: 122-4.

73. Savic L, Savic S, Hopkins PM. Anaphylaxis to sugammadex. Anaesth Intensive Care 2014; 42: 7-9.

74. Min KC, Bondiskey P, Schulz V, Woo T, Assaid C, Yu W, et al. Hypersensitivity incidence after sugammadex administration in healthy subjects: a randomised controlled trial. Br J Anaesth 2018; 121: 749-57.

75. de Kam PJ, Nolte H, Good S, Yunan M, Williams-Herman DE, Burggraaf J, et al. Sugammadex hypersensitivity and underlying mechanisms: a randomised study of healthy non-anaesthetised volunteers. Br J Anaesth 2018; 121: 758-67.

76. Ho G, Clarke RC, Sadleir PH, Platt PR. The first case report of anaphylaxis caused by the inclusion complex of rocuronium and sugammadex. A A Case Rep 2016; 7: 190-2.

77. Yamaoka M, Deguchi M, Ninomiya K, Kurasako T, Matsumoto M. A suspected case of rocuronium-sugammadex complex-induced anaphylactic shock after cesarean section. J Anesth 2017; 31: 148-51.

78. Ko MJ, Kim YH, Kang E, Lee BC, Lee S, Jung JW. Cardiac arrest after sugammadex administration in a patient with variant angina: a case report. Korean J Anesthesiol 2016; 69: 514-7.

79. Lee SH, Kim JY, Kim S, Sohn JT. The effect of sugammadex on the vascular tone of isolated rat aorta. Korean J Anesthesiol 2018; 71: 242-3.

80. Yang HS, Kim HJ, Koh W. Effects of sugammadex on the coronary circulation: direct effects on coronary vessels or hypersensitivity (Kounis syndrome)? Korean J Anesthesiol 2017; 70: 363-4.

81. Kikura M, Suzuki Y, Nishino J, Uraoka M. Allergic acute coronary artery stent thrombosis after the administration of sugammadex in a patient undergoing general anesthesia: a case report. A A Pract 2019; 13: 133-6.

82. Lee JH, Lee JH, Lee MH, Cho HO, Park SE. Postoperative negative pressure pulmonary edema following repetitive laryngospasm even after reversal of neuromuscular blockade by sugammadex: a case report. Korean J Anesthesiol 2017; 70: 959 .

83. Amao R, Zornow MH, Cowan RM, Cheng DC, Morte JB, Allard MW. Use of sugammadex in patients with a history of pulmonary disease. J Clin Anesth 2012; 24: 289-97.

84. Suzuki M, Inagi T, Kikutani T, Mishima T, Bito H. Negative pressure pulmonary edema after reversing rocuronium-induced 
neuromuscular blockade by sugammadex. Case Rep Anesthesiol 2014; 2014: 135032.

85. Eskander JP, Cornett EM, Stuker W, Fox CJ, Breehl M. The combination of sugammadex and desflurane may increase the risk of bronchospasm during general anesthesia. J Clin Anesth 2017; 41: 73.

86. Lee W. The potential risks of sugammadex. Anesth Pain Med 2019; 14: 117-22.

87. Cammu G. Sugammadex: appropriate use in the context of budgetary constraints. Curr Anesthesiol Rep 2018; 8: 178-85.

88. Baete S, Vercruysse G, Vander Laenen M, De Vooght P, Van Melkebeek J, Dylst D, et al. The effect of deep versus moderate neuromuscular block on surgical conditions and postoperative respiratory function in bariatric laparoscopic surgery: a randomized, double blind clinical trial. Anesth Analg 2017; 124: 1469-75.

89. Staehr-Rye AK, Rasmussen LS, Rosenberg J, Juul P, Lindekaer AL, Riber C, et al. Surgical space conditions during low-pressure laparoscopic cholecystectomy with deep versus moderate neuromuscular blockade: a randomized clinical study. Anesth Analg 2014; 119: 1084-92.

90. Cho YJ, Paik H, Jeong SY, Park JW, Jo WY, Jeon Y, et al. Lower intra-abdominal pressure has no cardiopulmonary benefits during laparoscopic colorectal surgery: a double-blind, randomized controlled trial. Surg Endosc 2018; 32: 4533-42.

91. Söderström CM, Borregaard Medici R, Assadzadeh S, Følsgaard S, Rosenberg J, Gätke MR, et al. Deep neuromuscular blockade and surgical conditions during laparoscopic ventral hernia repair: a randomised, blinded study. Eur J Anaesthesiol 2018; 35: 876-82.

92. Oh SK, Kwon WK, Park S, Ji SG, Kim JH, Park YK, et al. Comparison of operating conditions, postoperative pain and recovery, and overall satisfaction of surgeons with deep vs. no neuromuscular blockade for spinal surgery under general anesthesia: a prospective randomized controlled trial. J Clin Med 2019; 8: 498.

93. Mulier JP, Dillemans B. Anaesthetic factors affecting outcome after bariatric surgery, a retrospective levelled regression analysis. Obes Surg 2019; 29: 1841-50.

94. Kim NY, Koh JC, Lee KY, Kim SS, Hong JH, Nam HJ, et al. Influence of reversal of neuromuscular blockade with sugammadex or neostigmine on postoperative quality of recovery following a single bolus dose of rocuronium: a prospective, randomized, double-blinded, controlled study. J Clin Anesth 2019; 57: 97 102.
95. Boon M, Martini C, Yang HK, Sen SS, Bevers R, Warlé M, et al. Impact of high- versus low-dose neuromuscular blocking agent administration on unplanned 30-day readmission rates in retroperitoneal laparoscopic surgery. PLoS One 2018; 13: e0197036.

96. Oh TK, Oh AY, Ryu JH, Koo BW, Song IA, Nam SW, et al. Retrospective analysis of 30-day unplanned readmission after major abdominal surgery with reversal by sugammadex or neostigmine. Br J Anaesth 2019; 122: 370-8.

97. Chae YJ, Joe HB, Oh J, Lee E, Yi IK. Thirty-day postoperative outcomes following sugammadex use in colorectal surgery patients; retrospective study. J Clin Med 2019; 8: 97.

98. Lu IC, Chang PY, Su MP, Chen PN, Chen HY, Chiang FY, et al. The feasibility of sugammadex for general anesthesia and facial nerve monitoring in patients undergoing parotid surgery. Kaohsiung J Med Sci 2017; 33: 400-4.

99. Lu IC, Lin IH, Wu CW, Chen HY, Lin YC, Chiang FY, et al. Preoperative, intraoperative and postoperative anesthetic prospective for thyroid surgery: what's new. Gland Surg 2017; 6: 469-75.

100. Empis de Vendin O, Schmartz D, Brunaud L, Fuchs-Buder T. Recurrent laryngeal nerve monitoring and rocuronium: a selective sugammadex reversal protocol. World J Surg 2017; 41: 2298-303.

101. Bailey CR. Sugammadex: when should we be giving it? Anaesthesia $2017 ; 72: 1170-5$.

102. de Boer HD, Carlos RV, Brull SJ. Is lower-dose sugammadex a cost-saving strategy for reversal of deep neuromuscular block? Facts and fiction. BMC Anesthesiol 2018; 18: 159.

103. Muramatsu T, Isono S, Ishikawa T, Nozaki-Taguchi N, Okazaki J, Kitamura Y, et al. Differences of recovery from rocuronium-induced deep paralysis in response to small doses of sugammadex between elderly and nonelderly patients. Anesthesiology 2018; 129: 901-11.

104. Fuchs-Buder T. Less is not always more: sugammadex and the risk of under-dosing. Eur J Anaesthesiol 2010; 27: 849-50.

105. Kheterpal S, Vaughn MT, Dubovoy TZ, Shah NJ, Bash LD, Colquhoun DA, et al. Sugammadex versus neostigmine for reversal of neuromuscular blockade and postoperative pulmonary complications (STRONGER): a multicenter matched cohort analysis. Anesthesiology 2020; 132: 1371-81.

106. Bartels K, Hunter JM. Neostigmine versus sugammadex: the tide may be turning, but we still need to navigate the winds. $\mathrm{Br}$ J Anaesth 2020; 124: 504-7. 